Moreh, Chris ORCID:

https://orcid.org/0000-0002-7739-1455 (2019) Online survey design and implementation: targeted data collection on social media platforms. Sage Research Methods Cases . Sage

Downloaded from: http://ray.yorksj.ac.uk/id/eprint/3500/

The version presented here may differ from the published version or version of record. If you intend to cite from the work you are advised to consult the publisher's version: http://methods.sagepub.com/Cases

Research at York St John (RaY) is an institutional repository. It supports the principles of open access by making the research outputs of the University available in digital form. Copyright of the items stored in RaY reside with the authors and/or other copyright owners. Users may access full text items free of charge, and may download a copy for private study or non-commercial research. For further reuse terms, see licence terms governing individual outputs. Institutional Repository Policy Statement

\title{
RaY
}

Research at the University of York St John

For more information please contact RaY at ray@yorksj.ac.uk 


\title{
SAGE Research Methods Cases
}

\section{Online survey design and implementation: targeted data collection on social media platforms}

Contributor: Chris Moreh

York St John University, UK

Email: c.moreh@yorksj.ac.uk

Academic Level: Intermediate Undergraduate

\begin{abstract}
This case study describes an exploratory research project undertaken in a short period of time using online survey methodology. The project aimed to understand the attitudes and potential actions of EU migrants living in the UK in the months before the 2016 British referendum on EU membership. The case describes in detail the context of the project, the reasons for the chosen research design, and practicalities involved in designing the questionnaire, recruiting participants on online platforms such as Facebook, and the use of survey administration software.
\end{abstract}

\section{Learning Outcomes}

By the end of this case, students should be able to:

- Evaluate the strengths and weaknesses of online surveys

- Formulate research questions that can be answered through survey methodology

- Design different types of questionnaire questions

- Understand issues related to sampling and recruiting participants in online contexts 


\section{Case Study}

\section{The context}

In May 2015 the Prime Minister of the United Kingdom announced that a referendum will be held on the question of the country's continued membership of the European Union (EU), an intergovernmental organization it had joined in 1973. It was common knowledge that alongside elevated philosophical concerns such as those relating to 'sovereignty', 'immigration' from other EU member countries was an important reason for the growing Euroscepticism among the British public. According to EU law, citizens of an EU member state can easily move to another member state and enjoy equal rights to the citizens of that country, and the UK had seen a significant increase of such EU movers to its territory in the decade following the 2004 enlargement of the EU to include the formerly socialist countries of Central and Eastern Europe.

When the referendum was announced, around 2,795,000 non-British EU nationals were living in the UK (Office for National Statistics 2016), and migration scholars like myself were extremely interested to find out how they felt about the upcoming vote, and what they might do in the case of a vote for 'Brexit' (a neologism referring to the possibility of BRitain EXITing the European Union); they were, after all, the segment of the UK population that would be most immediately affected by a decision to leave the EU, as this would end their (EU) citizenship rights on the territory of the UK. But what is the best strategy to approach such a vague research question?

In December 2015 I joined a research team that had just won a grant to explore the topic. There was a sense of urgency to the project, as the referendum was widely expected to be held in a few months' time - it indeed took place on 23 June 2016 -, and one of our aims was to inform policy debates in the run-up to the vote. We had six months to design the research, collect the data, analyze the results, and write up the findings in a convincing way. The situation was not unlike that in which many dissertation students might find themselves.

\section{Research design}

Right from the start of the project we faced several conundrums:

- We were aiming to understand the opinions and expected behaviour of a heterogeneous population of almost three million members. In statistical terms, therefore, our 'population' was not the entire population of the United Kingdom, but a specific group of resident foreigners whose main shared characteristic was that they held EU citizenship rights that were being threatened by the referendum. At the same time, previous research - including my own - had emphasised the various sociological differences between the members of this population (Moreh 2014); and 
these differences were important to explore. But how could we achieve a sample that is representative enough to inform policymakers?

- Our research questions were rather exploratory in nature. There was no previous research that would directly underpin our concerns. In these conditions, what are the most appropriate questions to ask, and how to ask them? Should we think of predetermined questions in the form of a structured interview or questionnaire, or is it more useful to collect answers to open-ended questions in a qualitative interview format?

- Related to the above issues concerning research strategy and sampling, there was also the question of how to reach and recruit our potential participants, and collect our data in a short timeframe and with limited financial resources.

As in the case of most research projects, the way forward was through compromise. Having considered our options, we concluded that the most useful method to achieve our purposes was an online survey. The advantages we saw in this method were the following:

- It's cheap (it doesn't have to cost anything, really) and fast (see Greenlaw and BrownWelty 2009);

- It can help recruit hard-to-reach participants and can have wide geographical coverage (Temple and Brown 2011);

- The number of internet users has significantly increased over the past decade, reducing the 'coverage bias' that was once considered as 'innate' to online surveys (Couper 2000; Sue and Ritter 2012); migration researchers have also shown that migrants are increasingly relying on online social networks to obtain information and stay connected to their families and other co-nationals in the countries of origin and destination (Dekker and Engbersen 2014; Moreh 2014);

- And it can produce both quantitative and qualitative data (Smyth et al. 2009).

At the same time, online surveys have several limitations and pitfalls that we needed to consider. In this case study I describe some of the considerations we had to make while designing and conducting our online survey, and will highlight a few issues that we faced.

\section{Research practicalities}

\section{From research questions to questionnaire questions}

The online survey is a questionnaire-based instrument, yet the questionnaire allows for significant flexibility. It should consist primarily of closed questions, but it also offers the possibility to collect textual information through open-ended questions. Given that respondents self-administer the questionnaire at a time and in an environment that is most convenient for them, these open-ended questions can actually generate very important and 


\section{Figure 1: Two core questions of the survey}

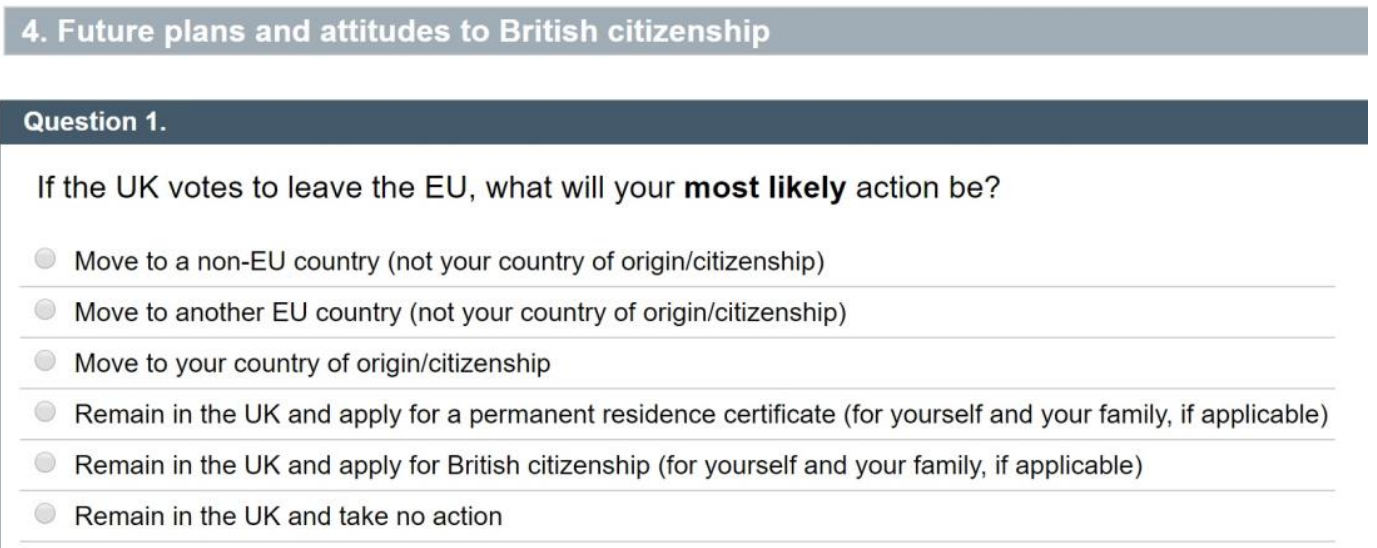

\section{Question 2.}

Regardless of the EU referendum, what is your most likely plan for the next 5 years?

Move to a non-EU country (not your country of origin/citizenship)

Move to another EU country (not your country of origin/citizenship)

Move to your country of origin/citizenship

Remain in the UK and apply for a permanent residence certificate (for yourself and your family, if applicable)

Remain in the UK and apply for British citizenship (for yourself and your family, if applicable)

Remain in the UK without any concrete plan

useful information, especially when the project is somewhat exploratory. The disadvantage is, of course, that the researcher cannot react to the information provided and the 'communication' is one-sided. Open questions are thus most useful when employed to clarify or expand on answers given to closed questions, but can also be used to collect more substantial textual data, and methodological research has shown that certain design 'tricks' can improve the response rate and the quality of responses (see Smyth et al. 2009) .

Most important when designing the questions of a questionnaire is to make them useful for your explanatory purposes. Team conversations in the first month of the project focused on this issue. As mentioned earlier, we were interested both in general attitudes towards the EU referendum and the possible steps in reaction to it. Given that the political decision taken at the referendum would affect the legal status - i.e. the citizenship rights - of our target population, our starting assumption was that in reaction to the possible changes EU migrants have four concrete legal options: (1) to apply for a Permanent Residence Certificate (which they did not need before); (2) to apply for British citizenship; (3) to leave the country; or (4) not to take any action at all. The two core questions of the questionnaire addressed these options: one question asked about planned actions in case of a vote for Brexit, and another one asked about plans for the next five years regardless of the EU referendum (Figure 1). Our basic idea was that by comparing the answers to these two questions we could identify some of the effects that the referendum - and a Brexit vote in particular - may have on EU migrants, and highlight these in terms that are relevant to policymakers (for example, by 
pointing to an expected increase in citizenship applications that may put strains on public administration).

However, in order to obtain data that allows an academically sophisticated analysis, a series of other questions also needed to be considered. For instance, while policymakers may only be interested in knowing whether British citizenship applications would increase in the near future, migration scholars are interested in understanding the reasons and circumstances under which naturalization decisions are taken, or the meaning attributed by social actors to the legal-political concept of 'citizenship'.

Despite ditching many of the questions that had initially been thrown into the hat, the main body of the final questionnaire contained a total of 194 question 'items' organized in four sections. We combined a variety of question types, including question blocks containing several items, as shown in Figure 2. We also included two optional open-ended questions with text response boxes at the end of two sections, where respondents could write freely about any issues that our questions may have missed (Figure 2).

We estimated that the questionnaire should take around 20-25 minutes to complete, which is a significant time commitment. This would probably lower the completion rate (i.e. the number of surveys completed divided by the number of surveys started), but would increase the complexity of the data obtained. It was one compromise to be made, and I'll discuss in the concluding section whether we made the right choice.

\section{From paper to software}

The questionnaire was initially developed on paper. Designing a set of questions that make sense to respondents while at the same time relating directly to the conceptual framework of the research is hard work, and one should expect to devote a significant amount of time to this phase. In our case, it took almost two months, one-third of the total length of the research project.

Besides individual questions, we also had to consider the overall flow of the questionnaire: the most appropriate way to order the questions, and how specific answers determine future questions. For instance, we included a dichotomous question (i.e. a question with only two answer options: yes/no) asking if the respondent is planning to apply for British citizenship at any point in the future. This question appeared in a different section than our two core questions (cf. Figure 1 above), and was intended to check more general attitudes towards naturalization, not limited to the next five years or the outcome of the EU Referendum. It could also serve to check if there is logical consistency in the answers provided (for example, if someone responded that they planned to naturalize as British citizens in the next five years regardless of the Referendum, but then later stated that they are not planning to apply for British citizenship at any point in the future, this raises alarms; luckily only $0.8 \%$ of our respondents answered inconsistently). But we were also interested in the reasons behind 


\section{Figure 2: Example of question block and open-ended question}

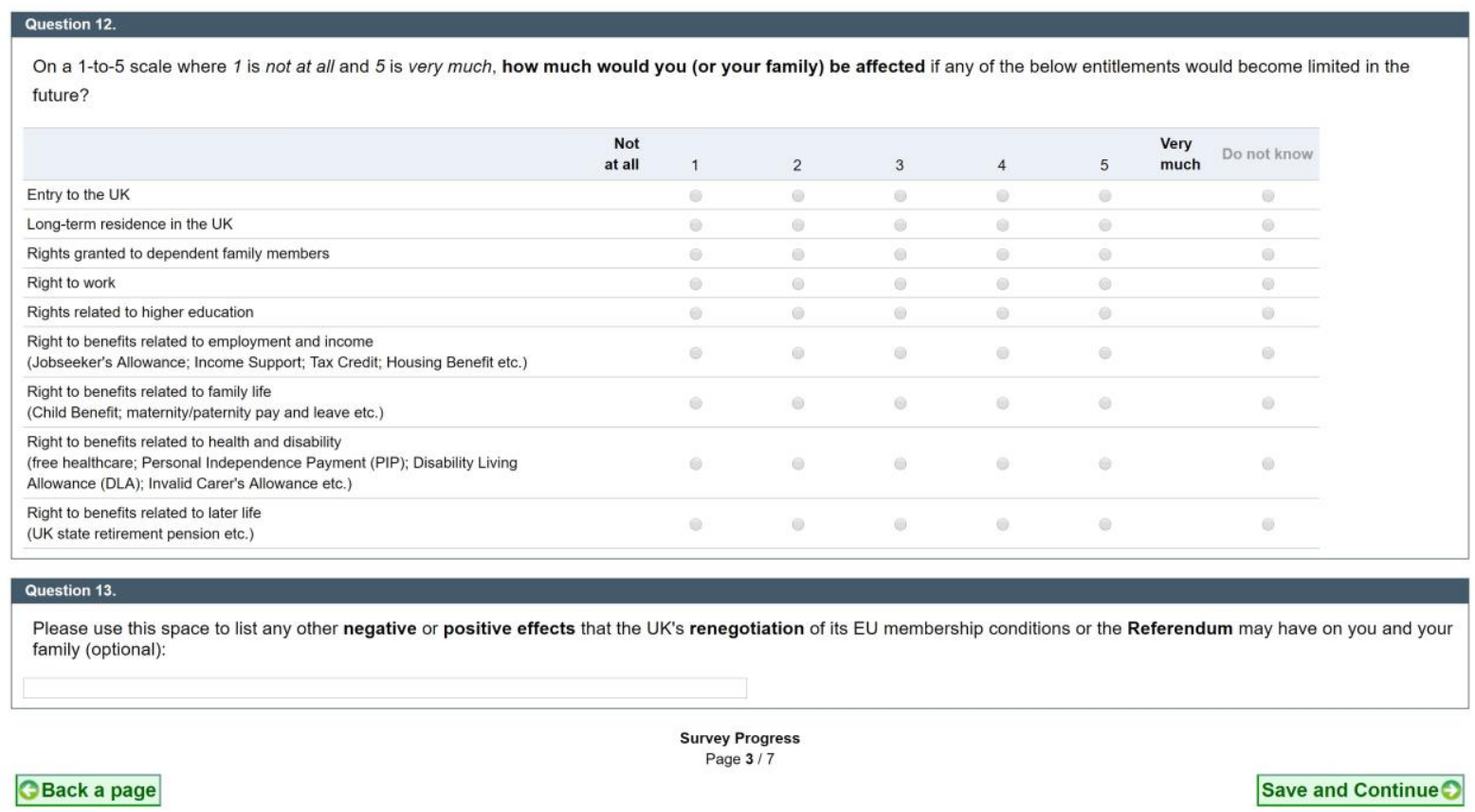

attitudes towards naturalization, and the reasons for or against naturalization can be different. So, depending on the answer given, we asked a different set of follow-up questions.

The great advantage of online surveys is that they can seamlessly incorporate such 'skip patterns': those who answered 'yes' would only see the follow-up question that is relevant to them, skipping the question relevant to those who answered 'no'. This logic can also be applied to entire sections. For example, we had decided that our target population was EU migrants living in the UK who did not hold British citizenship; but given that our survey may reach some of those who had recently become British citizens, we were also interested in understanding their motivations and did not want to exclude them. Following a start page that described the project and asked participants to tick a box agreeing to participate, the first section of the survey was therefore meant to ensure that the respondent qualifies to take part in the survey. Figure 3 shows a part of the paper-based questionnaire plan describing how answers to the initial screening questions would determine the skip pattern of the survey, and what should happen if the person attempting to complete the survey turns out not to satisfy the requirements for participation.

Any online survey software should provide options for managing the flow of the questions, but before planning your survey you should familiarize yourself with the options provided by your software of choice. Some free plans of popular survey platforms - such as SurveyMonkey - can be highly limited, not only in respect to the types and number of questions permitted, but also the total number of viewable responses. It is always advisable to use one of the platforms that your institution subscribes to (Qualtrics is quite popular with universities, and it is a powerful platform). In our case, we used a survey platform designed in-house by the Psychology and IT departments at the University of Southampton, where the 
project was based. We have tested out the system several times, and even so some technical issues were only identified while piloting the survey.

Conducting a pilot study with a small number of participants is crucial. We piloted our survey on 15 qualifying postgraduate students at the university. This preliminary step helped identify some technical glitches that we had missed, as well as questions that proved less straightforward to the pilot participants than they had been to the research team. In light of the feedback received, we were able to make final amendments to the questionnaire. However, technical problems arising from the software used can never be fully eliminated, and I'll mention some of the mistakes we made in the concluding section.

\section{The target population}

Online surveys have been described as particularly useful for accessing hidden and hard-toreach populations such as drug users (see Miller and Sønderlund 2010; Temple and Brown 2011). Our target population was less 'hidden', yet it would take considerable effort and time to reach participants in offline settings. Data from large national surveys - such as the Census or the Labour Force Survey - offer a good insight into the overall number of EU migrants of different nationalities and their main demographic characteristics, but pay-for-access databases held by marketing research companies - such as Qualtrics's own - are unlikely to deliver a representative sample. In fact, upholding the sampling standards of classical survey research would be very difficult with online surveys such as ours. As most studies using such methods conclude, 'the internet is a useful tool for reaching hidden populations, but is likely to impose some bias in samples when seeking generalizable data' (Miller and Sønderlund 2010: 1565).

We had some information about the population of EU migrants in the UK when we started the project. We knew that citizens of Poland, Ireland, Romania, Portugal and Italy represented the five most numerous nationality groups. Since it would be almost impossible to achieve a representative sample for all nationalities, we decided to focus on these largest communities (excluding Irish nationals who, for historical reasons, have a different legal status in the UK compared to other continental Europeans). We knew that these countries of origin have joined the EU at different times, and therefore their citizens would have different migration experiences. At the same time, we also knew that within nationality groups there is great variety in social backgrounds, occupational characteristics and, importantly, the level of English language knowledge. Again, further compromises had to be made.

Two main practicalities determined our sampling considerations: (1) access to participants and (2) access to target languages. We decided to translate the questionnaire into the languages of the largest nationality groups to make sure that proficient knowledge of English language is not a determining factor in participation. With limited amount of money to spend on translators, we had to be selective in respect to the number of languages. Also, having examined the online migrant landscape, we realized that some nationality groups are difficult to reach, as their online presence - community-specific Facebook groups, migrant newspapers, ethnic businesses, associations etc. - is limited. 


\section{Figure 3: Screening questions with skip pattern}

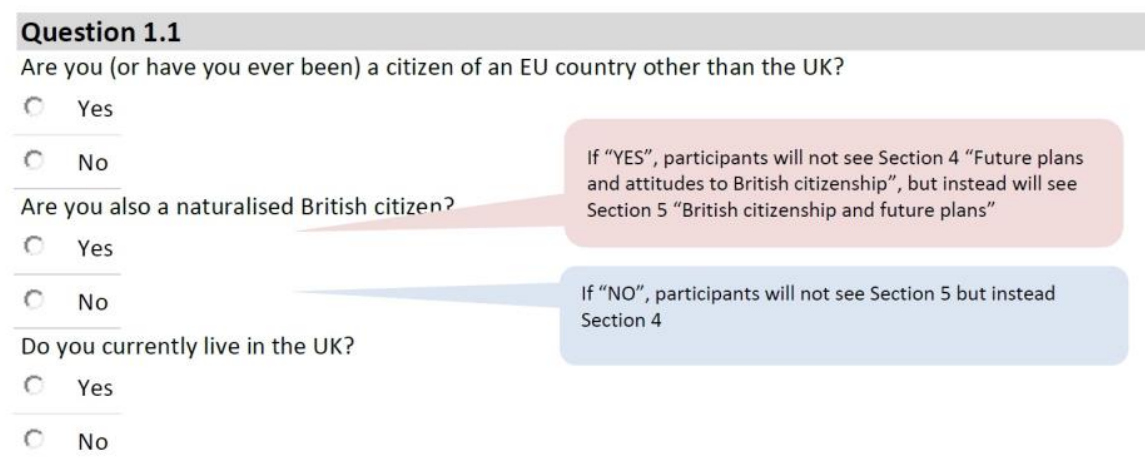

IF "NO" to first question, then:

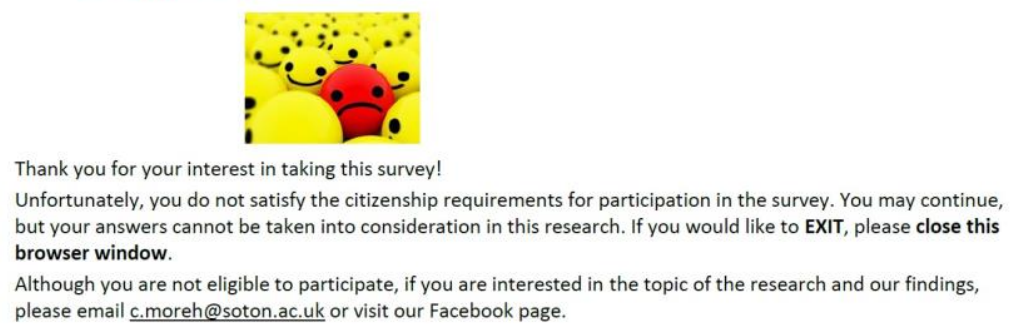

Running a survey in different languages is always complicated by the fact that subtle meanings can get lost in translation. There is no easy way out of this problem. To minimize these risks, we recruited bilingual translators from among our graduate students, who were interested in social research and were willing to have one-to-one meetings to discuss their translations in detail. I could translate the questionnaire into Romanian, Hungarian and Spanish myself, and we were able to recruit student translators for Polish, Portuguese and Italian. In this way we could target the four largest EU migrant groups in their own languages. With the English version of the survey we also aimed to reach other groups particularly German, Dutch and French nationals, who are the most numerous EU migrant groups from the pre-Enlargement North-Western European member states -, while being aware that the data obtained in that way will have to be analyzed with caution. Our sampling choice already restricted the generalizability of our data, and the actual data collected will introduce further limitations.

\section{Method in Action}

\section{Collecting the data}

Since the success of our data collection depended on successfully recruiting a relevant number of respondents, at the stage of designing the project we compiled a list of all the online channels that we could potentially access. These were mostly discussion boards, advertisement webpages, online media outlets, social media groups and migrant associations. We e-mailed the editors of migrant newspapers and representatives of associations, providing 
them with a description of our project and asking if they could disseminate our survey. Four UK-based online migrant news portals (two Polish, one Romanian and one Portuguese) agreed to publish brief news stories that incorporated a link to our survey.

Facebook also provides access to various groups with names such as 'POLACY W UK' ('Poles in the UK', over 14,000 members) or 'Portugueses na Inglaterra' ('Portuguese in England', over 3,000 members). We identified over 40 such groups for our target population, and for the duration of the data collection period I posted the link to the survey once or twice per week. Since posting in these groups is often only open for group members, when joining the groups I contacted the moderators and requested permission to post the link to the survey in the group. In all but three cases permission was granted, and in most cases each post needed to be approved by one of the moderators before it went live. To catch the attention of potential respondents, I prepared short texts inviting people to fill in the survey. These were also translated into the different languages. Typical calls - shown here with instructions for the translators - read:

"The referendum on whether Britain will remain a member of the European Union is fast approaching! As an EU citizen living in the UK, how does this affect you? Fill in our online survey for a chance to win a $£ 100$ voucher to spend in a store of your choice: [link] [use the most common name for UK, Britain etc. in the target language]"

Or

"The University of Southampton is running a survey to find out the opinions of [target nationality group; e.g. Portuguese] citizens about the British referendum on EU membership. Please fill in our online survey for a chance to win a $£ 100$ voucher to spend in a store of your choice, and send the link to anyone else who might be interested: [link]"

We were aiming to collect as many responses as possible, so we had decided to offer a small financial incentive. A single participant would be randomly selected at the end of the project to win a shopping voucher worth $£ 100$. This is often referred to as a 'sweepstakes incentive', as opposed to an individual incentive where each completed survey earns a small amount. Although we can think of many pros and cons in offering financial incentives, the type of incentive we chose is less likely to motivate participants to fill in the survey more than once, while still offering the excitement of potentially winning something tangible. Unfortunately, there is no way to assess whether the incentive has actually helped collect more responses.

However, by offering the incentive we had to consider further ethical issues. Although survey participants were guaranteed anonymity, in order to contact the winner we needed their email address. To ensure that this does not discourage participation in the survey, we made participation in the prize draw and the provision of an e-mail address optional. We also reassured participants that their e-mail addresses would only be used for the purpose of getting in touch should they win, and that they would be deleted from our database once the prize is allocated. 


\section{Assessing the data}

The survey generated a total of 1,695 submitted questionnaires. However, I had to ensure that these are valid and error-free. The process of cleansing a raw dataset such as the one you obtain when downloading and importing your data from the surveying software into a dataanalysis software like SPSS is long and tedious, and you should allow a substantial amount of time for this process. We first had to exclude a number of cases for various reasons:

- Some surveys were completed in too short a time for the questions to have been read and understood thoroughly. The average time of completion was 25 minutes, with a minimum of 6 and a maximum of 111, and a standard deviation of 14.2 minutes. We examined and excluded most cases where the questionnaire was completed in less than 10 minutes;

- Some respondents may have completed the survey more than once. Ensuring that each case is individual is not an easy task with online surveys, but it is necessary, especially if financial incentives were offered. In our assessment we relied on the following information: IP address, completion time, main demographic characteristics, e-mail address, unanswered questions and logically conflicting answers.

- Some respondents answered incorrectly to one of the screening questions (cf. Figure 3 above) and were directed to the wrong subsequent section of the survey. In other cases - especially when the English version of the survey was used - due to missing answers to personal information questions it could not be assessed whether the response to the screening questions was accurate and true.

Following this basic cleansing of the data we retained 1,585 cases. The overall majority of our respondents were Polish nationals $(\mathrm{N}=915,58 \%)$. The number of Hungarian $(\mathrm{N}=142$, 9\%), Portuguese $(\mathrm{N}=140,9 \%)$ and Romanian $(\mathrm{N}=138,9 \%)$ respondents was more or less even. The remaining $15 \%$ of respondents consisted of German $(\mathrm{N}=82)$, Spanish $(\mathrm{N}=50)$, Italian $(\mathrm{N}=32)$, French $(\mathrm{N}=21)$, Dutch $(\mathrm{N}=20)$ and other $(\mathrm{N}=45)$ nationals. A total of 40 participants also held British citizenship and we excluded them from most of our analyses.

It is obvious that data collection from some nationality groups was more successful than from others; for instance, responses from Italian and Spanish nationals were disappointingly low despite using translated questionnaires. If the aim was to compare the attitudes of different nationals, then this data would not be satisfactory. Our aims, however, were somewhat broader, yet for some analyses it proved advisable to focus on Poles alone (McGhee, Moreh and Vlachantoni 2017), or on selected nationalities (Moreh, McGhee and Vlachantoni 2016).

But how representative is our data in respect to some important social and demographic characteristics? To assess this, we compared our data to that of the Quarterly Labour Force Survey for the period April-June 2016. 
Table 1: Comparison of participants' demographic characteristics with data from the Quarterly Labour Force Survey (April-June 2016)

\begin{tabular}{|l|c|c|c|c|}
\hline & \multicolumn{2}{|c|}{ Our survey (N=1526) } & \multicolumn{2}{c|}{ LFS (N=2392) } \\
\hline & $\mathbf{N}$ & $\mathbf{\%}$ & $\mathbf{N}$ & \% \\
\hline Female & 979 & $64 \%$ & 1285 & $54 \%$ \\
\hline Married, in civil partnership, cohabitating & 993 & $65 \%$ & 1747 & $73 \%$ \\
\hline Has children & 730 & $48 \%$ & 1216 & $51 \%$ \\
\hline Age group: & & & & \\
\hline Under 30 & 294 & $19 \%$ & 592 & $25 \%$ \\
\hline $30-39$ & 679 & $44 \%$ & 961 & $40 \%$ \\
\hline $40-49$ & 389 & $25 \%$ & 505 & $21 \%$ \\
\hline Over 50 & 158 & $10 \%$ & 334 & $14 \%$ \\
\hline UK Country: & & & & \\
\hline England & 1265 & $83 \%$ & 2127 & $89 \%$ \\
\hline Wales & 48 & $3 \%$ & 54 & $2 \%$ \\
\hline Scotland & 182 & $12 \%$ & 134 & $6 \%$ \\
\hline Northern Ireland & 23 & $2 \%$ & 77 & $3 \%$ \\
\hline Educational qualification & & & & \\
\hline Vocational & 164 & $11 \%$ & 333 & $14 \%$ \\
\hline Secondary & 478 & $31 \%$ & 171 & $7 \%$ \\
\hline Post-secondary further & 225 & $15 \%$ & 150 & $6 \%$ \\
\hline Undergraduate higher & 286 & $19 \%$ & 352 & $15 \%$ \\
\hline Postgraduate higher & 326 & $21 \%$ & 312 & $13 \%$ \\
\hline Other or unknown & 47 & $3 \%$ & 1074 & $45 \%$ \\
\hline Economic activity: & & & & \\
\hline Employed full time & 931 & $61 \%$ & 1334 & $56 \%$ \\
\hline Employed part-time & 214 & $14 \%$ & 308 & $13 \%$ \\
\hline Self-employed & 138 & $9 \%$ & 293 & $12 \%$ \\
\hline Inactive & 157 & $10 \%$ & 457 & $19 \%$ \\
\hline Time in UK: & & & & \\
\hline$<3$ years & 398 & $26 \%$ & 421 & $18 \%$ \\
\hline 3-6 years & 347 & $23 \%$ & 423 & $18 \%$ \\
\hline 6-9 years & 317 & $21 \%$ & 363 & $15 \%$ \\
\hline 9+ years & 451 & $30 \%$ & 1151 & $49 \%$ \\
\hline Ner & & & & \\
\hline
\end{tabular}

Notes:

Percentages are in respect to column and variable totals (i.e. remaining differences to $100 \%$ are due to 'missing', 'other' and 'prefer not to say' responses).

Students are excluded from both samples. Only the nine nationalities mentioned are included in both samples.

LFS source: ONS 2016b

We see in Table 1 that our data shows a marked gender imbalance, with women making up $64 \%$ of our sample compared to $54 \%$ in the LFS sample. We expected this, as previous research had repeatedly shown that women tend to be more connected in online spaces than men (Kimbrough et al. 2013), and this is a general limitation for online surveys.

In terms of age our participants were also less diverse, showing that online surveys attract fewer participants under 30 or over 50. The geographical balance of our data was good, this being one of the identified strengths of online surveys (Temple and Brown 2011). 
In terms of educational level, we believe our data is stronger than those from national surveys, because the latter do not accurately record the qualification held by migrants. The share of those whose qualification was recorded as 'other' or 'unknown' by the LFS was $45 \%$. However, given that graduate-level qualifications are easier to compare internationally, there is reason to believe that most of the misreported qualifications are for lower levels of education, so our data is still tilted towards the higher educated. It also somewhat overrepresents the economically active and those who migrated to the UK more recently.

Nevertheless, overall, the survey managed to collect data that is comparable with those collected through other methodologies, and the differences and possible implications can be carefully considered when analyzing the data and writing up the results.

\section{Practical Lessons Learned}

In the Research Practicalities section, I highlighted three dimensions of the research project, and each of these raised some unanswered questions. The practical lessons to be learned relate to these.

The first issue concerned the complexity of the survey, and whether it affected the completion rate. On the one hand, the data we obtained has allowed us to perform a series of multivariate analyses through which we could identify and discuss complex relationships. The qualitative data we gathered was much richer than expected, allowing us to analyze it and assess it on its own (McGhee, Moreh and Vlachantoni 2018). Some peripheral questions - such as one on attitudes towards healthcare - provided such interesting data that a new research project grew out of it (Moreh, McGhee and Vlachantoni 2018). As an exploratory project the data collection was very successful.

On the other hand, the overall completion rate was dismally low: 15,942 people had clicked the survey link, and only $11 \%$ of them completed the survey. But the overwhelming majority of those who landed on the survey start page did not go on to answer even one of the introductory questions on the following page. If we only count those who answered at least the first question of the survey, the completion rate is actually 59\%. One possible conclusion is that it was less the length of the survey that determined the completion rate, but the general interest in the research following its description on the start page.

The first lesson, nevertheless, is to keep the research focused and simple. Although a more complex questionnaire worked well for our exploratory purposes, most dissertation projects should focus on a clearly defined question. When designing the questionnaire, think very carefully about the minimum number of questions that are necessary and sufficient to answer the research question, and stick to them. It is also recommended to reflect the simplicity of the survey on the opening description page as well.

The second lesson is to familiarize yourself with the survey software you are using. As noted earlier, it is almost impossible to avoid all technical difficulties, and even having piloted the 
survey I managed to overlook some issues. For example, as it was shown in Figure 2 above, we included 'Do not know' answer options for many of our questions. Our software had a separate setting to include such options, and that is why it appears faded in Figure 2 (i.e. it was not part of the scale, but a separate option). However, the software mixed these answers together with missing answers, so there was no easy way to distinguish between those who answered that they 'do not know' and those who did not bother answering at all. Luckily the number of missing answers was generally low, but important information has been lost in this way, and it would have been easily avoidable had we known from the start how the software deals with these answer options.

The final lesson is that cleansing the dataset and understanding your data in depth before performing the analysis is not only crucial but also time well invested. Working with data from specially designed online surveys has the great advantage that you already have an intimate understanding of how the data was collected and the logic behind the questions. Online surveys are very unlikely to generate data that are generalizable, but thinking carefully about the limits of the data obtained can also help identify aspects and contexts in which they are generalizable, and therein lies the strength of most quantitative projects.

\section{Exercises and Discussion Questions}

1. What research strategy would you have used for the above described research project? Discuss it with the person sitting next to you, arguing for either a qualitative, quantitative or mixed strategy. Evaluate their relative advantages and disadvantages, trying to convince your conversation partner.

2. Have another look at Figures 1 and 2. What types of questions do they contain? Can you think of other types of questions? Why do we need different question types, what is their purpose? (Consult Chapter 11: Asking questions in Bryman 2016)

3. Try to come up with a simple research question that can be answered through survey methodology. Write down a few questions that you would include in a questionnaire in order to answer your research question. How many questionnaire questions are necessary and enough to address the research question? Compare and discuss your cases with the person sitting next to you.

4. Think of a simple research question that can be answered through online survey methodology. Who is your target population, and how would you sample your participants? What difficulties do you foresee? (Consult Chapter 8: Sampling in quantitative research in Bryman 2016)

5. What are the advantages and disadvantages of offering financial incentives in online surveys? Make a list of all the pros and cons that you can think of. 


\section{Further Readings}

Bryman, A. (2016). Social research methods (Fifth ed.). Oxford and New York: Oxford University Press (Part Two: Quantitative Research)

Toepoel, V. (2016). Doing surveys online. Thousand Oaks, CA: Sage.

\section{References}

Couper, M. (2000). Review: Web Surveys: A Review of Issues and Approaches. Public Opinion Quarterly, 64(4), 464-494. doi: 10.1086/318641

Dekker, R., \& Engbersen, G. (2014). How social media transform migrant networks and facilitate migration. Global Networks, 14(4), 401-418. doi: 10.1111/glob.12040

Greenlaw, C., \& Brown-Welty, S. (2009). A comparison of web-based and paper-based survey methods: testing assumptions of survey mode and response cost. Eval Rev, $33(5), 464-480$.

Kimbrough, A. M., Guadagno, R. E., Muscanell, N. L., \& Dill, J. (2013). Gender differences in mediated communication: Women connect more than do men. Computers in Human Behavior, 29, 896-900.

McGhee, D., Moreh, C., \& Vlachantoni, A. (2017). An 'undeliberate determinacy'? The changing migration strategies of Polish migrants in the UK in times of Brexit. Journal of Ethnic and Migration Studies, 43(13), 2109-2130. doi:

10.1080/1369183X.2017.1299622

McGhee, D., Moreh, C., \& Vlachantoni, A. (2018). Stakeholder identities in Britain's neoliberal ethical community: Polish narratives of earned citizenship in the context of the UK's EU referendum. The British Journal of Sociology. doi:10.1111/14684446.12485

Miller, P. G., \& Sønderlund, A. L. (2010). Using the internet to research hidden populations of illicit drug users: a review. Addiction, 105(9), 1557-1567. doi: 10.1111/j.13600443.2010.02992.x

Moreh, C. (2014). A Decade of Membership: Hungarian Post-Accession Mobility to the United Kingdom. Central and Eastern European Migration Review, 3(2), 79-104.

Moreh, C., McGhee, D. \& Vlachantoni, A. (2016). Should I stay or should I go? Strategies of EU citizens living in the UK in the context of the EU referendum. ESRC Centre for Population Change Briefing Papers, No. 35. Available at: https://eprints.soton.ac.uk/394152/1/BP35_Should_I_stay_or_should_I_go.pdf

Moreh, C., McGhee, D. \& Vlachantoni, A. (2018). EU migrants' attitudes to UK healthcare. ESRC Centre for Population Change Briefing Papers, No. 41. Available at: http://www.cpc.ac.uk/docs/BP41_Migrants healthcare.pdf

Office for National Statistics (2016a). Population of the United Kingdom by Country of Birth and Nationality (Online dataset). Retrieved 1 March 2017, from Office for National Statistics: https://www.ons.gov.uk/ 
Office for National Statistics (2016b). Quarterly Labour Force Survey, 1992-2016. [data collection]. UK Data Service. Retrieved from:

https://discover.ukdataservice.ac.uk/series/?sn=2000026

Smyth, J. D., Dillman, D. A., Christian, L. M., \& McBride, N. (2009). Open-Ended

Questions in Web Surveys: Can Increasing the Size of Answer Spaces and Providing Extra Verbal Instructions Improve Response Quality?, Public Opinion Quarterly, 73: $325-37$.

Sue, V. M., \& Ritter, L. A. (2012). Conducting online surveys (2nd ed.). Thousand Oaks, Calif.: Sage.

Temple, E. C., \& Brown, R. F. (2011). A Comparison of Internet-Based Participant Recruitment Methods: Engaging the Hidden Population of Cannabis Users in Research. Journal of Research Practice, 7(2), Article D2.

http://jrp.icaap.org/index.php/jrp/article/view/288/247 